\title{
ОСОБЕННОСТИ РАСТВОРЕНИЯ МЕТАЛЛИЧЕСКОГО РОДИЯ В КИСЛЫХ ОКИСЛИТЕЛЬНЫХ СРЕДАХ В ГИДРОТЕРМАЛЬНЫХ УСЛОВИЯХ
}

\author{
(C) Н. В. Белоусова 1 , О. В. Белоусов 1,2 , Р. В. Борисов $1,2 *$, Н. В. Гризан 1,2 \\ ${ }^{1}$ Сибирский федеральный университет, 660041, г. Красноярск, пр. Свободный, д. 79 \\ 2 Институт химии и химической технологии СО РАН - обособленное подразделение \\ ФИЦ КНЦ СО РАН, 660036, г. Красноярск, Академгородок, 50/24 \\ *E-mail: roma_boris@list.ru; ov_bel@icct.ru
}

Поступила в Редакцию 1 октября 2018 г.

После доработки 11 июня 2019 г.

Принята к публикации 26 июня 2019 г.

\begin{abstract}
Исследовано растворение металлического родия в растворах хлороводородной кислоты в гидротермальных автоклавных условиях. Изучено влияние различных факторов на глубину перевода родия(0) в раствор. Установлено, что количественное растворение родия(0) достигается в смеси хлороводородной и бромоводородной кислот в присутствии диоксида марганиа при $200^{\circ} \mathrm{C}$ в автоклавах. Полученные результаты могут быть использованы как для аналитического определения родия, так и в технологии переработки родийсодержащего сырья и синтезе комплексных соединений родия.
\end{abstract}

Ключевые слова: родий; растворение; гидротермальные условия

DOI: $10.1134 / \mathrm{S} 0044461819080073$

Хорошо известно, что металлы платиновой группы, в особенности родий и иридий, в обычных условиях химически весьма устойчивы к действию различных минеральных кислот и щелочей. При этом следует отметить, что смеси кислот способны частично растворять благородные металлы в дисперсном состоянии $[1,2]$. Разработка эффективных методов перевода объектов, содержащих родий, в удобные для дальнейших операций комплексные формы чрезвычайно актуальна в химическом анализе, аффинажном производстве для получения прекурсоров с целью последующего использования, например, при создании различных каталитических систем или в ювелирной промышленности. Наиболее широко для растворения металлического родия используют методы его сплавления с пероксидными соединениями, пиросульфатами щелочных металлов с дальнейшим растворением сульфатов родия в воде или кислотах
$[3,4]$. На аффинажных предприятиях применяют методы хлорирования платиновых металлов в различных модификациях, например, в присутствии галогенидов щелочных металлов. Для приготовления особо чистых растворов платиновых металлов применяют электролитические методы их растворения под действием постоянного или переменного тока в раствоpax минеральных кислот [4-6]. Так, специалистами AО «Екатеринбургский завод по обработке цветных металлов» разработана и внедрена эффективная технология получения родиевой хлористоводородной кислоты, которая предусматривает электрохлорирование порошка родия в растворе $\mathrm{HCl}[5,6]$.

На наш взгляд, для растворения металлов платиновой группы перспективно применение гидрометаллургических технологий. Так, показано [7], что в открытой системе при $65^{\circ} \mathrm{C}$ наилучший результат (85.6\%) по растворению родия из отрабо- 
танных катализаторов достигнут при использовании хлороводородной кислоты с добавками пероксида водорода. Однако здесь необходимо учитывать вероятность нахождения родия в состоянии, отличном от компактного, с чем как раз и может быть связана легкость его перевода в раствор. В нашей предыдущей работе [8] отмечено, что в мелкодисперсном состоянии растворяется даже иридий, но, правда, в автоклавных условиях, при температурах, близких к $200^{\circ} \mathrm{C}$. При этом, несмотря на жесткие окислительные условия, данный процесс протекает крайне медленно.

Достаточно часто процессы с участием металлов платиновой группы отличаются кинетической заторможенностью. Повышение температуры является одним из наиболее распространенных приемов интенсификации химических реакций, а использование закрытых реакторов (автоклавов) приводит к существенному улучшению показателей как с экологической, так и с экономической точки зрения. В связи с этим интерес к гидрометаллургическим автоклавным процессам чрезвычайно высок; в качестве примера выделим лишь некоторые работы, посвященные данной проблематике [8-11].

Большое влияние на процессы растворения оказывает выбор окислительной среды. В работах $[12,13]$ показана эффективность автоклавного разложения образцов хлорированием в смесях хлороводородной кислоты и перманганата калия. В [14] авторами детально исследованы процессы растворения платиновых концентратов и показано, что трехкомпонентная реакционная смесь, состоящая из $\mathrm{HCl}, \mathrm{H}_{2} \mathrm{O}_{2}$ и $\mathrm{MnO}_{2}$, существенно улучшает показатели вскрытия упорных концентратов сложного состава.

Таким образом, определение оптимальных условий (температура, выбор окислителя, продолжительность) количественного растворения металлического родия в гидротермальных условиях представляет практический интерес как для разработки аналитических методов его определения, так и для совершенствования процессов выщелачивания родия из промпродуктов аффинажного производства.

Цель настоящего исследования заключалась в установлении возможности количественного растворения металлического родия в автоклавных условиях при повышенных температурах.

\section{Экспериментальная часть}

В данной работе использовали: воду дистиллированную; $\mathrm{HCl}$ - ос.ч. 20-4; $\mathrm{H}_{2} \mathrm{O}_{2}$ (ГОСТ 177-88); $\mathrm{MnO}_{2}$ - ч.д.а.; $\mathrm{HBr}$ - х.ч.; $\mathrm{NaClO}_{3}$ - х.ч.; компакт- ный родий, полученный отжигом в атмосфере аргона родиевой черни по методике, описанной в работе [15]; аффинированный родий (ГОСТ 12342-2015; коммерческий продукт ОАО «Красцветмет»); пластинку родиевую толщиной 0.15 мм (доля родия не менее 99.9 мас\%).

Концентрацию родия в растворах определяли атомно-абсорбционным методом (спектрометр AAnalyst-400, Perkin Elmer, США). Размеры частиц и морфологию определяли методом сканирующей электронной микроскопии на приборе ТМ-3000 (Hitachi, Япония). Для компактного порошка родия, который был использован в настоящей работе, согласно электронно-микроскопическим данным, характерна сферическая форма частиц диаметром 0.9-1.2 мкм. Усредненный размер частиц аффинированного родия составляет 100 мкм. Рассчитанная удельная площадь родиевой пластинки $\left(0.001 \mathrm{M}^{2} \cdot \Gamma^{-1}\right)$ примерно в 5 и 500 раз меньше удельной поверхности аффинированного $\left(0.005 \mathrm{M}^{2} \cdot \Gamma^{-1}\right)$ и компактного (отожженного) $\left(0.5 \mathrm{M}^{2} \cdot \Gamma^{-1}\right)$ родия соответственно.

Эксперименты по растворению родия осуществляли в кварцевых автоклавах объемом от 20 до $30 \mathrm{~cm}^{3}$, конструкция которых описана в работах $[8,10]$. В кварцевый автоклав помещали металлический родий (в виде порошка или пластинки) в количестве от 10 до 100 мг, загружали окислитель, заливали 10 мл кислоты (хлороводородная или смесь хлороводородной и бромоводородной кислот). Кварцевый реактор закрывали фторопластовой крышкой, фиксировали в титановом кожухе [8]. Автоклав нагревали в термостате до заданной температуры при постоянном перемешивании в вертикальной плоскости. Конструкция автоклавов позволяет проводить эксперименты с разделением фаз, когда твердые реагенты помещаются в стаканчик, закрепленный в верхней части автоклава, а в кварцевый реактор заливаются жидкие реагенты. В данном случае смешение фаз осуществляли путем включения перемешивания после прогрева системы до требуемой температуры.

Отметим важную специфическую особенность используемых реакторов, а именно возможность визуального контроля за протекающим процессом. В ходе растворения наблюдали изменение окраски раствора от бесцветной (бледно-желтой) до темно-красной (красно-коричневой). После истечения заданного времени автоклав доставали, охлаждали. Осадок отделяли от раствора, многократно промывали дистиллированной водой до отрицательной реакции на хлорид-ион, высушивали до постоянной массы и взвешивали. Определяли химический состав раствора. 


\section{Обсуждение результатов}

Ввод хлора в автоклав можно осуществлять непосредственно в молекулярном (газообразном) состоянии, однако удобнее его вводить опосредованно, когда он выделяется в результате химической реакции, например, при взаимодействии диоксида марганца с хлороводородной кислотой:

$$
\mathrm{MnO}_{2}+4 \mathrm{HCl}=\mathrm{MnCl}_{2}+\mathrm{Cl}_{2}+2 \mathrm{H}_{2} \mathrm{O} .
$$

В солянокислых растворах процесс окисления металлического родия хлором термодинамически разрешен, однако вследствие кинетических затруднений в области умеренных температур он практически не протекает даже в случае родиевой черни. Авторы работы [14], детально изучая процесс пробоподготовки платиновых концентратов, в том числе и содержащих родий, показали возможность их вскрытия при температуре $180^{\circ} \mathrm{C}$. Однако следует отметить, что эти концентраты обладают большой удельной поверхностью (не менее $10 \mathrm{M}^{2} \cdot \Gamma^{-1}$ ), существенно более высокой, чем у порошка отожженного родия $\left(0.5 \mathrm{M}^{2 \cdot} \Gamma^{-1}\right)$ - самого дисперсного из образцов, используемых в настоящей работе. При этом концентраты являются материалами сложного химического состава (твердые растворы металлов платиновой группы друг с другом и цветными металлами), обладающими существенными неоднородностями как структурного, так и химического характера, что в свою очередь может приводить к эффектам внутреннего электролиза, благоприятно влияющего на показатели растворения.

Хорошо известно, что скорость растворения зависит от величины площади поверхности твердой фазы. В нашем случае даже для материала с относительно высокой поверхностью $\left(0.5 \mathrm{M}^{2} \cdot \Gamma^{-1}\right)$ при температуре $180^{\circ} \mathrm{C}$ не наблюдали растворения в растворах, содержащих хлороводородную кислоту и диоксид марганца. Повышение температуры до $190^{\circ} \mathrm{C}$ приводит к заметному вскрытию отожженного порошка родия. Схематично этот процесс можно описать уравнением

$$
\mathrm{Rh}+1.5 \mathrm{Cl}_{2}+3 \mathrm{HCl}=\mathrm{H}_{3} \mathrm{RhCl}_{6} .
$$

В этих условиях растворяется 80-85\% отожженного родиевого порошка в течение 5 ч.

Дальнейшее увеличение температуры до $200^{\circ} \mathrm{C}$ превышает достигнутые показатели вскрытия уже

$$
2 \mathrm{Rh}+\mathrm{NaClO}_{3}+12 \mathrm{HCl}=2 \mathrm{H}_{3} \mathrm{RhCl}_{6}+\mathrm{NaCl}+3 \mathrm{H}_{2} \mathrm{O} .
$$

Однако и в этом случае, несмотря на высокое значение окислительно-восстановительного потенциала после опыта $(+1050$ мВ относительно хлоридсере-

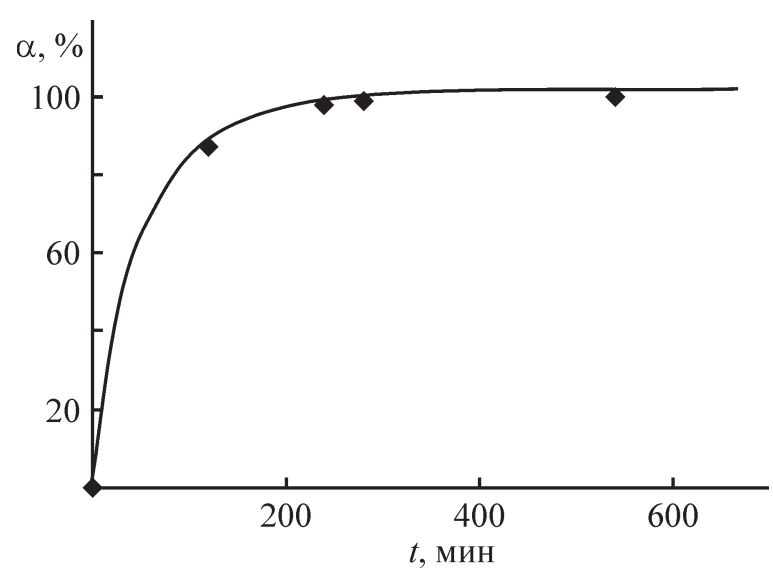

Рис. 1. Зависимость степени вскрытия отожженного $\mathrm{Rh}$-порошка в $6 \mathrm{M} \mathrm{HCl}+\mathrm{MnO}_{2}$ от времени при темпеpaтуре $200^{\circ} \mathrm{C}$.

через 2 ч, а близкие к количественному растворению результаты получены через 4 ч (рис. 1). Растворение (близкое к количественному) аффинированного родия при данной температуре происходит за время более 10 ч.

В случае с родиевой пластинкой следует ожидать ухудшения степени растворения. Действительно, при температуре $200^{\circ} \mathrm{C}$ через 8 ч в раствор перешло всего лишь $4 \%$ родия.

В работе [14] авторы показали, что добавление к смеси диоксида марганца и хлороводородной кислоты пероксида водорода ( $10 \%$ от общего количества реакционной смеси) приводит к более эффективному вскрытию концентратов благородных металлов. По мнению авторов, это связано с образованием в этом случае в качестве промежуточного продукта атомарного хлора, более реакционноспособного, чем молекулярный хлор. Введение в систему пероксида водорода (5 об\%) не привело к заметному увеличению степени растворения пластинки.

Использование альтернативных диоксиду марганца окислителей может привести к улучшению показателей растворения металлического родия. В качестве такого окислителя был рассмотрен хлорат натрия, имеющий в кислых средах более высокий окислительно-восстановительный потенциал, чем диоксид марганца. Процесс вскрытия родия можно представить следующим образом:

бряного электрода), повысить степень растворения родиевой пластинки не удалось. 


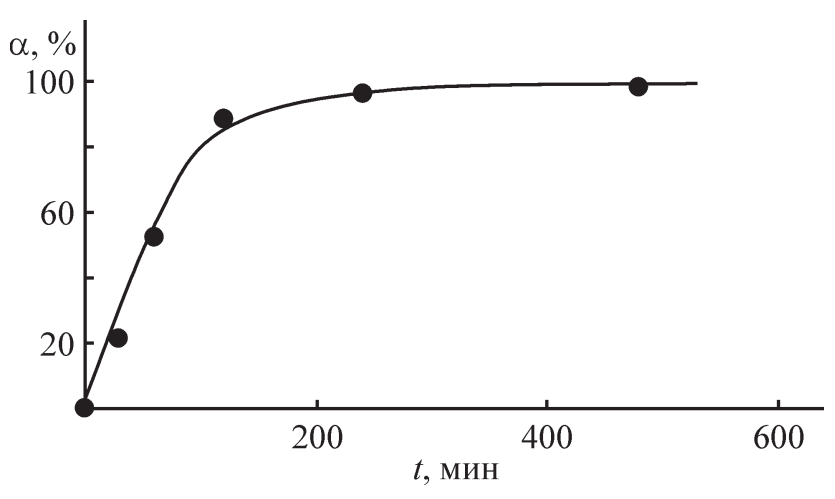

Рис. 2. Зависимость степени растворения родиевой пластинки в смеси $5.4 \mathrm{M} \mathrm{HCl}+0.6 \mathrm{M} \mathrm{HBr}+\mathrm{MnO}_{2}$ от времени при температуре $200^{\circ} \mathrm{C}$.

В работе [16] отмечено, что бромид-ионы ускоряют растворение благородных металлов в водных растворах. И действительно, ситуация изменяется при использовании в качестве реакционной среды смеси $6 \mathrm{M} \mathrm{HCl}+6 \mathrm{M} \mathrm{HBr}$ в соотношении 9:1 с добавлением диоксида марганца в полуторакратном избытке от стехиометрии. Уже через 1 ч при $200^{\circ} \mathrm{C}$ растворяется $60 \%$ родиевой пластинки после приведения их в контакт. При этом значение окислительно-восстановительного потенциала после опытов относительно хлоридсеребряного электрода составляет $+750 \mathrm{mB}$. Однако следует ожидать, что при термостатировании в автоклавных условиях при высокой температуре $\left(200^{\circ} \mathrm{C}\right)$ реализуются более высокие значения окислительно-восстановительного потенциала, чем измеряемые при комнатной температуре. Родиевая пластинка эффективно растворяется в смеси хлороводородной и бромоводородной кислот с использованием в качестве окислителя диоксида марганца, и через 2 ч около $90 \%$ родиевой пластинки переходит в жидкую фазу (рис. 2). В рассматриваемых условиях аффинированный родий количественно растворяется за 2 ч.

По сравнению с хлором элементарный бром имеет более высокую растворимость в хлороводородной кислоте, и как следствие реализуется возможность создания более высокой концентрации галогенидов в реакционной среде [17]. Бромид-ион взаимодействует с молекулярным хлором по реакции

$$
2 \mathrm{Br}^{-}+\mathrm{Cl}_{2}=\mathrm{Br}_{2}+2 \mathrm{Cl}^{-} \text {. }
$$

Летучесть брома существенно ниже летучести хлора, что в свою очередь приводит к меньшему давлению насыщенных паров в автоклаве.

Увеличение содержания $\mathrm{HBr}$ в 3 раза за счет изменения соотношения хлороводородной и бромоводородной кислот привело к уменьшению значения окислительно-восстановительного потенциала после проведения эксперимента на $100 \mathrm{MB}$, что составило +650 мВ относительно хлоридсеребряного электрода. Кроме того, зафиксировано снижение скорости растворения родиевой пластинки: за 4 ч растворилось около 90\% образца, в то время как при соотношении 9:1 за такое же время растворилось $>98 \%$. При этом количества родия и диоксида марганца оставляли прежними.

\section{Выводы}

$\mathrm{B}$ настоящей работе показана возможность и определены параметры (температура, время, влияние добавок окислителей) количественного растворения металлического родия как в виде компактных порошков, так и в виде пластинки в гидротермальных автоклавных условиях. Установлено, что аффинированный родий и родиевую пластинку можно растворить (более чем на 98\%) в смеси 6 М хлороводородной и бромоводородной кислот (9:1) с добавлением диоксида марганца при $200^{\circ} \mathrm{C}$ в течение 2 и 4 ч соответственно. Отожженная родиевая чернь растворяется при $200^{\circ} \mathrm{C}$ в растворе $6 \mathrm{M}$ хлороводородной кислоты с добавлением диоксида марганца в течение 4 ч.

\section{Благодарности}

Работа частично выполнена с использованием оборудования Красноярского регионального центра коллективного пользования ФИЦ КНЦ СО РАН. Выражаем благодарность заведующему лабораторией рентгеновских и спектральных методов анализа к.т.н. А. М. Жижаеву за проведение инструментальных исследований.

\section{Конфликт интересов}

Авторы заявляют об отсутствии конфликта интересов, требующего раскрытия в данной статье.

\section{Информация об авторах}

Белоусова Наталья Викторовна, зав. кафедрой металлургии цветных металлов СФУ, проф., д.х.н., ORCID: https://orcid.org/0000-0002-1355-7399

Белоусов Олег Владиславович, старший научный сотрудник, к.Х.н., ORCID: https://orcid.org/0000-00017778-5393

Борисов Роман Владимирович, научный сотрудник, к.X.H., ORCID: https://orcid.org/0000-0002-6137-0975

Гризан Наталья Васильевна, инженер, ORCID: https://orcid.org/0000-0001-7469-0081 


\section{Список литературы}

[1] Hodgson A. P. J., Jarvis K. E., Grimes R. W., Marsden $O . J$. Development of an iridium dissolution method for the evaluation of potential radiological device materials // J. Radioanal. Nucl. Chem. 2016. V. 307. N 3. P. 2181-2186. DOI: https://doi.org/10.1007/ s10967-015-4381-1

[2] Park J. C. Purification and recovery of rhodium metal by the formation of intermetallic compounds // Bull. Korean Chem. Soc. 2008. V. 29. N 9. P. 1787-1789. DOI: https://doi.org/10.5012/bkcs.2008.29.9.1787

[3] Saguru C., Ndlovu S., Moropeng D. A review of recent studies into hydrometallurgical methods for recovering PGMs from used catalytic converters // Hydrometallurgy. 2018. V. 182. P. 44-56. DOI: https:// doi.org/10.1016/j.hydromet.2018.10.012

[4] Upadhyay A., Lee J.-C., Kim E., Kim M. S., Kim B. Su., Kumar $V$. Leaching of platinum group metals (PGMs) from spent automotive catalyst using electro-generated chlorine in $\mathrm{HCl}$ solution // J. Chem. Technol. Biotechnol. 2013. V. 88. P. 1991-1999. DOI: https:// doi.org/10.1002/jctb.4057

[5] Воинов В. Н., Коник К. П., Кузас Е. А., Лобко С. В. Показатели технологии электрохлорирования порошка родия // Цвет. мет. 2016. № 9. С. 57-62. DOI: https://doi.org/10.17580/tsm.2016.09.08

[6] Лобко С. В., Кузас Е. А., Набойченко С. С., Воинов $B$. H. Электрохлорирование вторичного сырья, содержащего благородные металлы, с использованием объемного токоподвода // Цвет. мет. 2017. № 3. C. 45-49. DOI: https://doi.org/10.17580/tsm.2017.03.07

[7] Harjanto S., Cao Y., Shibayama A., Shibayama A., Naitoh I., Nanami T., Kasahara K., Fujita T. Leaching of Pt, Pd and Rh from automotive catalyst residue in various chloride based solutions //Materials Transactions. 2006. V. 47. N 1. P. 129-135. DOI: https://doi. org/10.2320/matertrans.47.129

[8] Борисов Р. В., Белоусов О. В., Дорохова Л. И., Жижаев $A$. М. Особенности растворения высокодисперсных порошков иридия в кислых средах. // Журн. Сиб. федерал. ун-та. Химия. 2017. Т. 10. № 3. C. 325-332. DOI: https://doi.org/10.17516/1998-28360029

[9] Jha M. K., Lee J. C., Kim M. S., Jeong J., Kim B. S., Kumar $V$. Hydrometallurgical recovery/recycling of platinum by the leaching of spent catalysts: A review// Hydrometallurgy. 2013. V. 133. P. 23-32. DOI: https:// doi.org/10.1016/j.hydromet.2012.11.012

[10] Белоусов О. В., Белоусова Н. В., Рюмин А. И., Борисов Р. В. Обогащение платино-палладиевого концентрата в гидротермальных условиях // ЖПХ. 2015. Т. 88. № 6. C. 984-987 [Belousov O. V., Belousova N. V., Ryumin A. I., Borisov R. V. Russ. J. Appl. Chem. 2015. V. 88. N 6. P. 1078-1081. DOI: https://doi.org/10.1134/S1070427215060300].

[11] Mahmoud M. H. H. Leaching platinum-group metals in a sulfuric acid/chloride solution// J. Miner. Met. Mater. Soc. 2003. V. 55 N 4. P. 37-40. DOI: https:// doi.org/10.1007/s11837-003-0086-y

[12] Белоусов О. В., Дорохова Л. И., Чмышкова Т. И., Жижаев А. М. Автоклавное вскрытие геологических проб золотосодержащих руд // Цвет. мет. 2005. № 3. C. $13-15$.

[13] Беляев В. Н., Владимирская И. Н., Колонина Л. Н., Ковалев Г. Г., Кузнечов Л. Б., Ширяева О. А. Вскрытие платиносодержащих материалов хлорированием в замкнутых системах // ЖАХ. 1985. T. 40. № 1. С. 135-140.

[14] Гильберт Э. Н., Шабанова Л. Н., Коваленко Н. Л., Бухбиндер Г. Н., Солдатенко Г. Г., Кабаева В. А. // Унифицированный химико-атомно-эмиссионный метод определелия благородных и цветных металлов в промышленных материалах // ЖАХ. 1991. T. 46. № 7. C. 1391-1402.

[15] Борисов Р. В., Белоусов О. В., Иртюго Л. А. Термостимулированные превращения высокодисперсных порошков металлов платиновой группы в атмосфере аргона // ЖФХ. 2014. Т. 88. № 10. C. 1542-1548. DOI: https://doi.org/10.7868/ S0044453714100082 [Borisov R. V., Belousov O. V., Irtyugo L. A. // Russ. J. Phys. Chem. A. 2014. V. 88. N 10. P. 1732-1738. DOI: https://doi.org/10.1134/ S0036024414100069].

[16] Pesic B., Sergent R. H. Reaction mechanism of gold dissolution with bromine // Metallurgical and Materials Transactions B. 1993. V. 24. N 3. P. 419431. DOI: https://doi.org/10.1007/BF02666424

[17] Lee J., Ilyas S. Gold Metallurgy and the Environment. 2018. Boca Raton: CRC Press. Ch. 6. P. 147. DOI: https://doi.org/10.1201/9781315150475 